\title{
Down-regulation of argininosuccinate synthetase is associated with cisplatin resistance in hepatocellular carcinoma cell lines: implications for PEGylated arginine deiminase combination therapy
}

Jennifer A McAlpine*, Hsin-Tze Lu, Katherine C Wu, Susan K Knowles and James A Thomson

\begin{abstract}
Background: Many advanced human tumors, including hepatocellular carcinomas (HCC) are auxotrophic for arginine due to down-regulation of argininosuccinate synthetase (ASS1), the rate-limiting enzyme in arginine synthesis. The arginine-lowering agent PEGylated arginine deiminase (ADI-PEG 20) has shown efficacy as a monotherapy in clinical trials for treating arginine-auxotrophic tumors and is currently being evaluated in combination with cisplatin in other cancer types. Epigenetic silencing via methylation of the ASS1 promoter has been previously demonstrated in other cancer types, and a reciprocal relationship between ASS1 expression and cisplatin resistance has also been observed in ovarian cancer. However, the mechanism of ASS1 down-regulation, as well as the correlation with cisplatin resistance has not been explored in HCC. The present study investigates ADI-PEG 20 and cisplatin sensitivities in relation to ASS1 expression in HCC. In addition, we show how this biomarker is regulated by cisplatin alone and in combination with ADI-PEG 20.
\end{abstract}

Methods: ASS1 protein expression in both untreated and drug treated human HCC cell lines was assessed by western blot. The correlation between ASS1 protein levels, ADI-PEG 20 sensitivity and cisplatin resistance in these cell lines was established using a luminescence-based cell viability assay. Epigenetic regulation of ASS1 was analyzed by bisulfite conversion and methylation-specific PCR.

Results: A good correlation between absence of ASS1 protein expression, ASS1 promoter methylation, sensitivity to ADI-PEG 20 and resistance to cisplatin in HCC cell lines was observed. In addition, cisplatin treatment down-regulated ASS1 protein expression in select HCC cell lines. While, at clinically relevant concentrations, the combination of ADI-PEG 20 and cisplatin restored ASS1 protein levels in most of the cell lines studied.

Conclusion: ASS1 silencing in HCC cell lines is associated with simultaneous cisplatin resistance and ADI-PEG 20 sensitivity which suggests a promising combination therapeutic strategy for the management of HCC.

Keywords: Arginine, Argininosuccinate synthetase, Arginine deiminase, Cisplatin, Hepatocellular carcinoma, Combination therapy

\footnotetext{
* Correspondence: jmcalpine@polarispharma.com

Department of Biology, Polaris Pharmaceuticals, 9373 Towne Center Drive, Suite \#150, San Diego, CA 92121, USA
} 


\section{Background}

Arginine, a semi-essential amino acid in humans, is critical for the growth of human cancers [1]. Tumoral down-regulation of the enzyme argininosuccinate synthetase (ASS1), the rate-limiting step in arginine synthesis, results in a critical dependence on extracellular arginine due to an inability to synthesize this amino acid from citrulline. Such a dependence on extracellular arginine is known as arginine auxotrophy. Many advanced human tumors more commonly associated with chemoresistance and poor clinical outcome, including hepatocellular carcinoma (HCC), melanoma, mesothelioma, pancreatic cancer, prostate cancer, renal cell carcinoma, sarcoma and small cell lung cancer, exhibit loss of ASS1 expression and are thus arginine auxotrophs [2-9]. Conversely, other tumor types such as colorectal, gastric and ovarian cancer tend to have higher expression of ASS1 $[10,11]$. The mycoplasma-derived enzyme, arginine deiminase (ADI-PEG 20), PEGylated to enhance bioavailability and reduce immunogenicity, selectively degrades arginine, resulting in cell death in tumors lacking ASS1 [12]. Several phase I/II clinical trials of ADI-PEG 20 in patients with HCC and metastatic melanoma have shown promising indication of clinical benefit and low toxicity in patients with ASS1-deficient tumors [13-18]. A recently completed phase II trial of single-agent ADIPEG 20 in ASS1-negative patients with mesothelioma also revealed encouraging efficacy results $[19,20]$.

The significance for ASS1 loss in cancer is currently unclear; however, several groups have revealed that reduced expression of ASS1 is a predictive biomarker for the development of metastasis and is associated with a worse clinical outcome [21-25]. Epigenetic silencing via methylation of the CpG islands within the ASS1 promoter accounts for loss of ASS1 expression in many solid tumors studied to date, including ovarian, malignant pleural mesothelioma, glioblastoma, myxofibrosarcoma and bladder, as well as in some lymphoid malignancies [4,22-24,26,27]. Interestingly, the methylation status of ASS1 has been linked to platinum resistance in ovarian cancer [22]. Furthermore, it was found that patients treated with first line platinum/paclitaxel for ovarian cancer had a poor overall and disease-free survival if the tumor exhibited methylated ASS1 compared to unmethylated ASS1 [22,28]. In addition, methylated ASS1 has been linked to increased proliferation and invasion of bladder cancer cells [24].

$\mathrm{HCC}$ is one of the most common cancers in the world, especially in Asia and Africa [29]. Cisplatin has been commonly used as a chemotherapeutic agent for HCC, but it has not satisfactorily improved the survival rate for patients with advanced HCC, either as a single agent or in combination, due to acquired or intrinsic drug resistance [30]. Intriguingly, drug resistance is an important contributor for treatment failure of ASS1-negative tumors by ADI-PEG 20, possibly due to re-expression of the once-silenced ASS1 that has been observed in melanoma cell lines [31-33]. To overcome this type of resistance, a second drug must be added to drive cell death. For example, it has been observed that the combination of ADI-PEG 20 and cisplatin can increase apoptosis in melanoma cell lines [34]. In addition, combined treatment of oxaliplatin and human arginase in HCC exhibited synergistic inhibiting effect on tumor growth [35], providing further support that a platinum and an arginine-deprivation agent would be a good combination in this cancer. ADI-PEG 20 is currently being utilized in several clinical trials, including a global phase III trial for $\mathrm{HCC}$ as a monotherapy, as well as in combination with cytotoxics such as cisplatin for the treatment of melanoma and ovarian cancer.

Previous work has shown that the sensitivity of HCC cell lines to ADI-PEG 20 is due to the absence of ASS1 [3]. However, the mechanism of ASS1 silencing, as well as the correlation with platinum resistance has not been explored in HCC. In addition, although ASS1 loss has been identified as a potential indicator of arginine auxotrophy in cancer, its regulation is complex and its use as a biomarker in combination therapy is unfamiliar. The current investigation was initiated to elucidate the relationship between ASS1 protein expression, ADI-PEG 20 sensitivity and cisplatin resistance, as well as to assess ASS1 regulation in response to cisplatin and in combination with ADI-PEG 20 in HCC. Utilizing several human HCC cell lines with varying amounts of ASS1, we report that ASS1 silencing confers sensitivity to ADIPEG 20 and resistance to cisplatin. A good correlation is also observed between the methylation status of the ASS1 promoter, sensitivity to ADI-PEG 20 and resistance to cisplatin. In addition, cisplatin treatment downregulates ASS1 protein expression in select HCC cell lines. Finally, the expression level of ASS1 during combination drug treatments with ADI-PEG 20 and cisplatin is cell line and concentration-dependent, but is predominantly dictated by ADI-PEG 20 at more clinically relevant concentrations. Taken together, our data indicate that ADI-PEG 20 and cisplatin will complement each other in a clinically relevant heterogeneous tumor, thus providing a rationale for combining these two drugs for the treatment of $\mathrm{HCC}$.

\section{Methods}

\section{Cell culture}

The following human HCC cell lines were obtained from Dr. Yuh-Shan Jou at the Institute of Biomedical Sciences, Academia Sinica, Taipei, Taiwan: Sk-Hep1, Huh7, Tong, HCC36, Hep3B, Malhavu, PLC5 and Huh6. The human HCC cell lines HepG2, SNU398 and SNU182 were from American Type Culture Collection (ATCC, Manassas, 
VA). A2780 is an ovarian cancer cell line (cisplatin sensitive) derived from a patient prior to treatment and A2780CR is a cisplatin-resistant cell line that was developed by exposure of the parent A2780 cell line to increasing concentrations of cisplatin. Both A2780 and A2780CR cell lines were obtained from Sigma-Aldrich (St. Louis, MO). The following cells were grown in Dulbecco's Modified Eagle Medium (DMEM) (Lonza, Allendale, NJ) containing $10 \%$ heat-inactivated fetal bovine serum (FBS; Life Technologies, Carlsbad, CA), 1\% L-glutamine (Life Technologies) and 1\% non-essential amino acids (NEAA, Life Technologies): Sk-Hep1, Huh7, Tong, HCC36, Hep3B, Malhavu, PLC5, Huh6 and HepG2. SNU398, SNU182 and the ovarian cell lines were maintained in RPMI 1640 (Lonza) with 10\% heat-inactivated FBS and 1\% L-glutamine. All cells were sub-cultured two times a week using trypsin/EDTA (Life Technologies) and were grown at $37^{\circ} \mathrm{C}$ in $5 \% \mathrm{CO}_{2}$.

\section{Cell viability assay}

Cell viability $\left(\mathrm{IC}_{50}\right)$ values for ADI-PEG 20 and cisplatin (Sigma-Aldrich) were determined using the CellTiter-Glo (CTG) luminescent cell viability assay (Promega, Madison, WI). Cells (3,000-6,000 cells/well) were plated in $100 \mu \mathrm{L}$ medium/well in 96-well black micro-clear plates (Greiner bio-one, Monroe, NC). Following overnight incubation at $37^{\circ} \mathrm{C}$ and $5 \% \mathrm{CO}_{2}$, cells were exposed to a range of drug concentrations from a $50 \mathrm{X}$ plate $(2 \mu \mathrm{L} /$ well). Each concentration of drug was added to duplicate wells. After $72 \mathrm{~h}$ incubation, $25 \mu \mathrm{L} /$ well of CTG reagent was added directly to the medium and the plates were shaken for $5 \mathrm{~min}$, resulting in cell lysis and the generation of a luminescent signal proportional to the amount of ATP present. The luminescence values were read on a SpectraMax M3 microplate reader (Molecular Devices, Sunnyvale, CA) and converted to a percent cell viability that was calculated relative to the viability in corresponding matched DMSO-treated cells, which was designated as $100 \%$ viable. $\mathrm{IC}_{50}$ values (concentration of drug that results in $50 \%$ of luminescence signal compared with the DMSO-treated control) were obtained from nonlinear regression analysis of concentration-effect curves using GraphPad Prism version 6.0 software (San Diego, CA).

\section{Immunoblot analysis}

Whole-cell extracts were made from 90\% confluent cultures of all human cells. Cells were lysed in RIPA buffer (Sigma-Aldrich), with added protease inhibitor cocktail (Roche Molecular Systems, Pleasanton, CA) and PMSF (Sigma-Aldrich). Total lysate protein was quantified using a Coomassie Plus (Bradford) Protein Assay Reagent (Pierce, Rockford, IL). Cell extracts $(20 \mu \mathrm{g})$ were run on NuPage 4-12\% Bis-Tris Gels (Life Technologies) and then transferred to PVDF membranes (Life Technologies). The membranes were blocked in TBST buffer (Tris-HCL, 0.1\% Tween) containing 5\% Blotting-Grade Blocker (Bio-Rad, Hercules, CA) for $2 \mathrm{~h}$ at room temperature and then probed using a mouse monoclonal antibody to ASS1 (Polaris Pharmaceuticals, in-house) at a dilution of 1:500. GAPDH was used as a loading control for each western blot, so the membranes were cut and also probed with a rabbit polyclonal antibody to GAPDH (Millipore, Billerica, MA) at a dilution of 1:10,000. The blots were incubated with both primary antibodies overnight at $4^{\circ} \mathrm{C}$ on a rocker. After washing with TBST buffer, the membranes were incubated with secondary antibodies: goat anti-mouse for ASS1 (Santa Cruz Biotechnology, Dallas, TX) $(1: 10,000)$ and goat anti-rabbit for GAPDH (Santa Cruz Biotechnology) $(1: 60,000)$ and incubated at room temperature for $1 \mathrm{~h}$. The secondary antibodies were detected using either the SuperSignal West Pico (GAPDH) or Femto (ASS1) Chemiluminescent Substrate (Pierce) and blots were read on a Bio-Rad ChemiDox XRS + System. ASS1 and GAPDH levels were quantified using Image Lab Software (Bio-Rad, Hercules, CA).

For ASS1 protein determination after cisplatin treatments or for ADI-PEG 20 and cisplatin combination analysis, the same procedure was used with the following modifications. Cells were plated in two identical 96-well plates: one for cell viability and/or normalization for cell numbers between wells (luminescence assay; see Methods above) and one for lysis (ASS1 detection). After $72 \mathrm{~h}$ drug treatments, lysates were made and probed for protein analysis. For ASS1 and GAPDH detection, media was removed and each well of the microplate was washed with $100 \mu \mathrm{L}$ of PBS buffer (Gibco by Life Technologies). NuPage LDS sample buffer $(30 \mu \mathrm{L}$ of $1 \mathrm{x}$ sample buffer, Life Technologies) containing $50 \mathrm{mM}$ DTT was then added to each well and the plate was wrapped in parafilm and frozen at $-80^{\circ} \mathrm{C}$ for at least one hour to ensure lysis. After lysis, the samples in each well were spun and then used for immunoblot analysis. To account for the different number of viable cells in each well of the microplate, samples were normalized using the relative luminescence values for each corresponding well of the identical microplate.

\section{Bisulfite modification and methylation-specific PCR}

The EZ DNA Methylation-Direct Kit (Zymo Research Corporation, Irvine, CA) was used to perform complete DNA bisulfite conversion directly from the human cell lines. This process converts unmethylated cytosine residues to uracil while methylated cytosine residues remain unchanged. In general, 10,000-40,000 cells ( 60-250 ng genomic DNA) were used as starting material for each cell line. Methylation-specific PCR (MSP) of a 188 bp fragment located between 300 and 500 bp downstream of the transcription start site (TSS) was then performed 
to determine the methylation status of the ASS1 promoter. Bisulfite-modified DNA (150 ng) was used as a template for PCR reactions with primers specific for methylated (M) or unmethylated (UM) sequences. Primer sequences are: (1) M forward: 5'-TTTTTTTCGTTG TTTATTTTTTAGTC-3'; (2) M reverse: 5'-CTAAAA TCCGATACCAAACGTT-3'; (3) UM forward: 5' -TTTT TGTTGTTTATTTTTTAGTTGA-3' and (4) UM reverse: 5' -AACCTAAAATCCAATACCAAACATT-3'. Primers were purchased from IDT Technologies (San Diego, CA). PCR conditions for the methylated primers were as follows: 8 cycles of $95^{\circ} \mathrm{C}$ for $2 \mathrm{~min}, 54.8^{\circ} \mathrm{C}$ for $30 \mathrm{sec}$ and $72^{\circ} \mathrm{C}$ for $30 \mathrm{sec}$ were followed by 32 cycles of $95^{\circ} \mathrm{C}$ for $30 \mathrm{sec}, 54.8^{\circ} \mathrm{C}$ for $30 \mathrm{sec}$ and $72^{\circ} \mathrm{C}$ for $30 \mathrm{sec}$, then a final extension at $72^{\circ} \mathrm{C}$ for $10 \mathrm{~min}$. The PCR conditions for the unmethylated primers were identical, except the annealing temperature was $48^{\circ} \mathrm{C}$ instead of $54.8^{\circ} \mathrm{C}$. The HotStarTaq d-Tect polymerase (EpiTect MSP kit; Qiagen, Valencia, CA) was used for the PCR reactions. The PCR samples were run on $2 \%$ pre-cast agarose E-gels (Life Technologies) containing a fluorescent stain for visualization. The human methylated and non-methylated DNA set (Zymo Research) were used as negative and positive controls for bisulfite conversion efficiency, and MSP was similarly performed using a set of control primers designed to amplify non-methylated, methylated and mixed methylation copies of the death-associated protein kinase 1 gene (DAPK1), with an expected size of $274 \mathrm{bp}$.

\section{Statistical analysis}

GraphPad Prism version 6.0 was used to test results for statistical significance. Differences in ASS1 levels between groups were analyzed using an unpaired two-tailed $t$-test. A p value $<0.05$ was set as a level of statistical significance. In determining statistical significance for ASS1 protein levels after cisplatin treatments or for ADI-PEG 20 and cisplatin combination analysis, each drug concentration was compared to the untreated, or zero drug, sample to attain a $\mathrm{p}$ value for that particular drug concentration.

\section{Results}

\section{ASS1 deficiency confers sensitivity to ADI-PEG 20 and} resistance to cisplatin

To study the relationship between ASS1 expression and sensitivity to ADI-PEG 20 and cisplatin, we first screened 11 human HCC cell lines for this protein. The western blot shown in Figure 1A reveals the different amount of ASS1 protein in select cell lines. The signal intensity of the bands were quantified and normalized by taking the level of ASS1 in the HepG2 cell line as 1. For simplicity, the cell lines were categorized into one of four groups and are designated as either ASS1-high, medium, low or negative (Table 1). ASS1 expression allows cells to utilize citrulline as a substrate for arginine synthesis. ASS1-negative and low lines should thus be sensitive to ADI-PEG 20, while ASS1-high cell lines should be resistant to this drug. As expected, the ASS1-negative and low cell lines Sk-Hep1, SNU398 and Tong are very sensitive to ADIPEG 20, with $\mathrm{IC}_{50}$ values around $1 \mathrm{nM}(0.05 \mu \mathrm{g} / \mathrm{mL}$; Table 1). Cell lines that have some ASS1, designated as ASS1-medium, are less sensitive to ADI-PEG 20, while the ASS1-high cell lines are resistant to this drug. Figure $1 \mathrm{~B}$ displays ADI-PEG $20 \mathrm{IC}_{50}$ curves for three representative HCC cells lines: Sk-Hep1, HepG2 and Malhavu. As shown, the ADI-PEG 20 curve for the ASS1negative Sk-Hep1 cell line is very steep, with only $5-10 \%$ cell viability remaining at the highest concentration of ADI-PEG 20 (100 nM; $5 \mu \mathrm{g} / \mathrm{mL})$, while this drug only kills $50 \%$ of the ASS1-medium HepG2 cells at the same concentration. In contrast, the ASS1-high line Malhavu is completely resistant to ADI-PEG 20.

A reciprocal relationship between ASS1 expression and platinum resistance has been previously observed in ovarian cancer $[22,36]$. Interestingly, the HCC cell lines also show different sensitivity to cisplatin depending on the level of ASS1 present in each line. All of our ASS1negative or low cell lines are resistant to cisplatin, with Tong and Sk-Hep1 both having an $\mathrm{IC}_{50}$ value above $30 \mu \mathrm{M}$ (Table 1). The ASS1-high cell lines are at least 5 to 10 -fold more sensitive to cisplatin, with $\mathrm{IC}_{50}$ values in the low micromolar for most. Figure $1 \mathrm{C}$ shows cisplatin $\mathrm{IC}_{50}$ curves for three representative HCC cells lines: SkHep1, HepG2 and Malhavu. Surprisingly, this reciprocal trend between ASS1 expression and cisplatin resistance that we observe in our HCC cell lines is not seen with other platinum therapies such as oxaliplatin and carboplatin, or other chemotherapies such as doxorubicin, docetaxel, 5-FU or gemcitabine (data not shown). In addition, cisplatin $\mathrm{IC}_{50}$ values have been obtained for multiple cell lines from three other cancer types (colorectal cancer, melanoma and non-small cell lung cancer) and no such trend is observed, at least in the cell lines tested (data not shown). Thus, this reciprocal relationship between ASS1 expression and cisplatin may be exclusive to HCC and ovarian cancer. In summary, our data thus far indicate that ADI-PEG 20 is effective at killing ASS1-negative HCC cells, while cisplatin is effective at killing ASS1positive HCC cells. This observation suggests that their combination should be an efficacious treatment for heterogeneous cell populations that exist in tumors.

\section{Methylation status of the ASS1 promoter correlates with sensitivity to ADI-PEG 20 and resistance to cisplatin}

Epigenetic silencing via promoter $\mathrm{CpG}$ methylation in cell lines lacking ASS1 expression has been demonstrated in multiple cancer types [4,22-24,26,27]. A strong correlation between the methylation of the ASS1 promoter and sensitivity to ADI-PEG 20 has been established in these various 

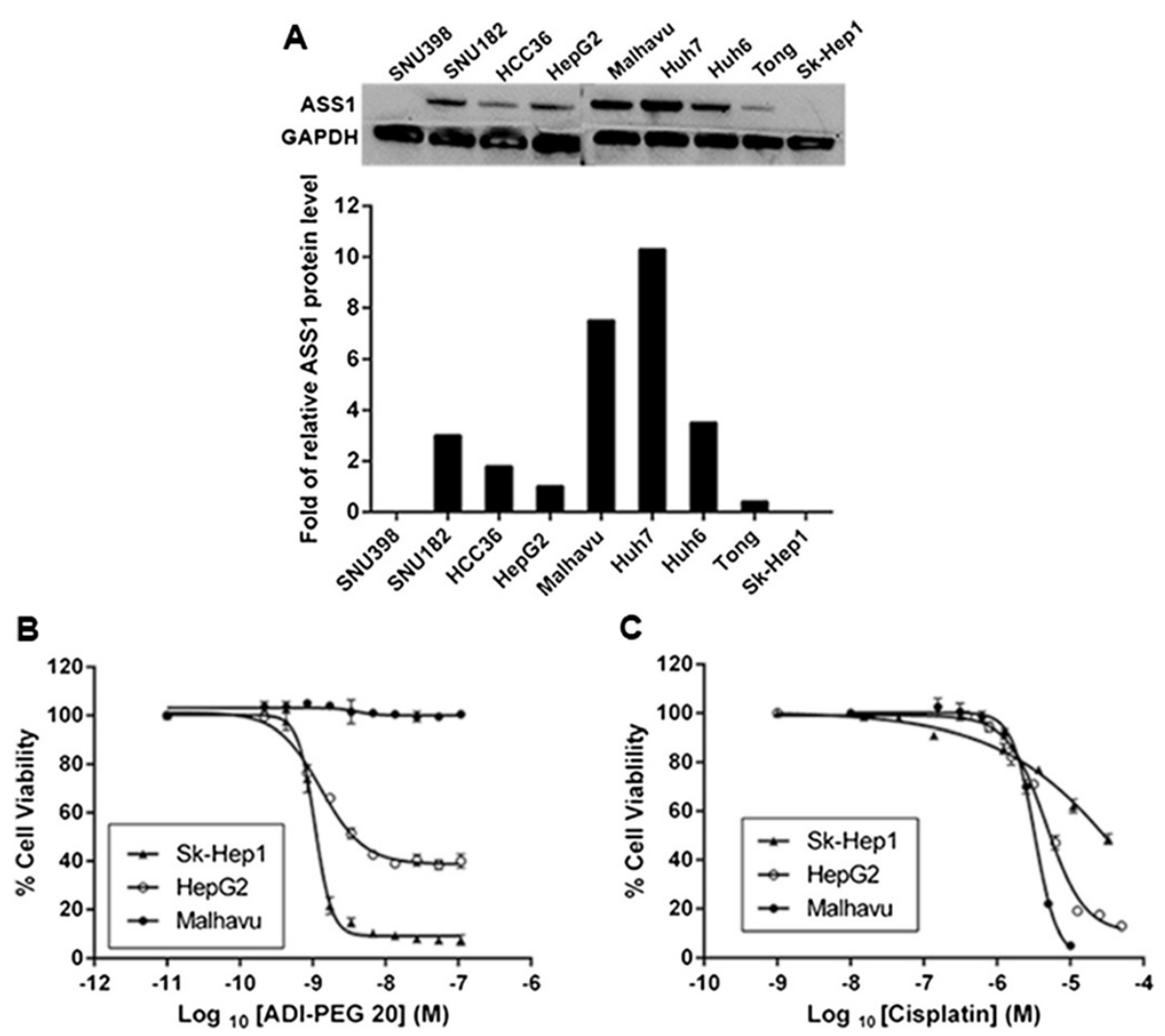

Figure 1 Effect of ASS1 expression on the sensitivity of HCC cell lines to ADI-PEG 20 and cisplatin treatment. (A) ASS1 protein levels from cell lysates were determined by western blot. GAPDH was run as a loading control. The signal intensities of the bands were quantified and normalized by taking the level of HepG2 cells as 1. (B and C) Sensitivity of three representative HCC cell lines to ADI-PEG 20 and cisplatin. Cells were cultured in medium containing various concentrations of (B) ADI-PEG 20 and (C) cisplatin. Duplicate samples were assessed for cell viability after $72 \mathrm{~h}$ using the Promega luminescence assay. Percent cell viability from either ADI-PEG 20 or cisplatin-treated cells was calculated relative to the viability in corresponding matched DMSO-treated cells, which was designated as $100 \%$. The data are representative of three or more independent experiments. Error bars represent S.D.

cancer cell lines. In addition, an important role for ASS1 in regulating platinum sensitivity via DNA methylationdependent epigenetic regulation of the ASS1 promoter has been observed in ovarian cancer [22]. This study demonstrated the presence of methylated CpG dinucleotides in the ASS1 promoter of a cisplatin resistant A2780CR cell line, while the parental A2780 line was essentially unmethylated. Using the A2780 and A2780CR ovarian cell lines as controls, we show the ASS1 DNA in the A2780 cell line is entirely unmethylated, while it is almost completely methylated in the A2780CR cell line (Figure 2A). To determine if our ASS1-negative HCC cisplatin-resistant cell lines are epigenetically regulated, we examined the methylation status of the ASS1 promoter in the Sk-Hep1 and SNU398 cell lines. As expected, both of these cisplatin-resistant, ASS1-deficient cell lines are completely methylated at the ASS1 promoter (Figure 2B), confirming that the silencing of ASS1 in these HCC cell lines is indeed epigenetic-based. In addition, Sk-Hep1 and SNU398 are very sensitive to arginine deprivation, demonstrating that methylation of the ASS1 promoter also correlates with sensitivity to ADI-PEG 20 in HCC. Furthermore, all of our ASS1-positive HCC cell lines are unmethylated (Figure 2C), display sensitivity to cisplatin, and are increasingly resistant to ADI-PEG 20. Surprisingly, the ASS1 promoter is entirely unmethylated in the Tong cell line (Figure 2B), even though these cells contain very little ASS1 protein, are resistant to cisplatin and sensitive to ADI-PEG 20 (Table 1 and Figure 1A). Overall, in $\mathrm{HCC}$, we observe a good association between the methylation status of the ASS1 promoter, ADI-PEG 20 sensitivity and cisplatin resistance in six out of the seven cell lines tested.

\section{Cisplatin treatment down-regulates ASS1 in ASS1-positive HCC cell lines}

We have previously demonstrated a reciprocal relationship between ASS1 expression and cisplatin resistance in our HCC cell lines. Therefore, we next investigated whether treatment with cisplatin could down-regulate 
Table 1 Sensitivity of human HCC cell lines to ADI-PEG 20 and cisplatin treatment

\begin{tabular}{cccc}
\hline $\begin{array}{c}\text { Cell } \\
\text { line }\end{array}$ & $\begin{array}{c}\text { ASS1 } \\
\text { level }\end{array}$ & $\begin{array}{c}\text { ADI-PEG 20 } \\
\mathbf{I C}_{\mathbf{5 0}}(\mathbf{n M})\end{array}$ & $\begin{array}{c}\text { Cisplatin } \\
\mathbf{I C}_{\mathbf{5 0}}(\boldsymbol{\mu} \mathbf{M})\end{array}$ \\
\hline Huh7 & High & $>10^{\mathrm{a}}$ & $2.7 \pm 0.3$ \\
Malhavu & High & No curve & $3.3 \pm 0.2$ \\
Huh6 & High & No curve & $2.9 \pm 0.8$ \\
SNU182 & High & No curve & $1.3 \pm 0.3$ \\
Hep3B & High & $>10^{\mathrm{a}}$ & $0.36 \pm 0.02$ \\
PLC5 & High & No curve & $2.2 \pm 0.3$ \\
HCC36 & Medium & $2.4 \pm 0.3$ & $2.9 \pm 1.2$ \\
HepG2 & Medium & $1.4 \pm 0.2$ & $4.7 \pm 0.4$ \\
Tong & Low & $1.3 \pm 0.1$ & $>30^{\mathrm{b}}$ \\
Sk-Hep1 & Negative & $1.1 \pm 0.1$ & $>30^{\mathrm{b}}$ \\
SNU398 & Negative & $1.2 \pm 0.1$ & $23 \pm 7.8$ \\
\hline
\end{tabular}

HCC cells were treated with various concentrations of either ADI-PEG 20 or cisplatin and the Promega luminescence assay was performed. $I C_{50}$ was calculated on replicates ( $n=3$ to 4 , mean \pm SD).

${ }^{a}$ No good $I C_{50}$ fit: approximately $25-30 \%$ loss of cell viability by $10 \mathrm{nM}$ ADI-PEG 20

${ }^{\mathrm{b}}$ No good $I C_{50}$ fit: lower limit. the ASS1 expression in three representative ASS1positive HCC cell lines: HepG2, HCC36 and SNU182. Cells were treated in 96-well microplates with increasing cisplatin concentrations for $72 \mathrm{~h}$, and luminescence values, indicative of cell viability, were then used to load similar amounts of protein across all of the cisplatintreated wells. ASS1 protein expression was subsequently determined by immunoblot analysis and normalized to GAPDH protein at each cisplatin concentration. Figure 3 (A and B) shows that ASS1 protein expression is progressively reduced in both the HepG2 and HCC36 cell lines as the cisplatin concentration is increased. The $\mathrm{IC}_{50}$ values for cisplatin in the HepG2 and HCC36 cell lines are $4.7 \mu \mathrm{M}$ and is $2.9 \mu \mathrm{M}$, respectively. Thus, the ASS1 levels drop by approximately $50 \%$ relative to zero drug at this concentration of cisplatin in the HepG2 cell line and $40 \%$ in the HCC36 cells (Figure 3A and B). Further increasing the cisplatin results in even less ASS1 expression, with approximately 70\% down-regulation of ASS1 by $30 \mu \mathrm{M}$ cisplatin in HepG2 cells (Figure 3A). We also studied the ASS1 expression level with cisplatin in the SNU182 cell line, which has the lowest $\mathrm{IC}_{50}$ value for cisplatin $(1.3 \mu \mathrm{M})$ of the three cell lines we chose to investigate. Because cisplatin is more potent in this cell line than the others, there is significant cell death at the
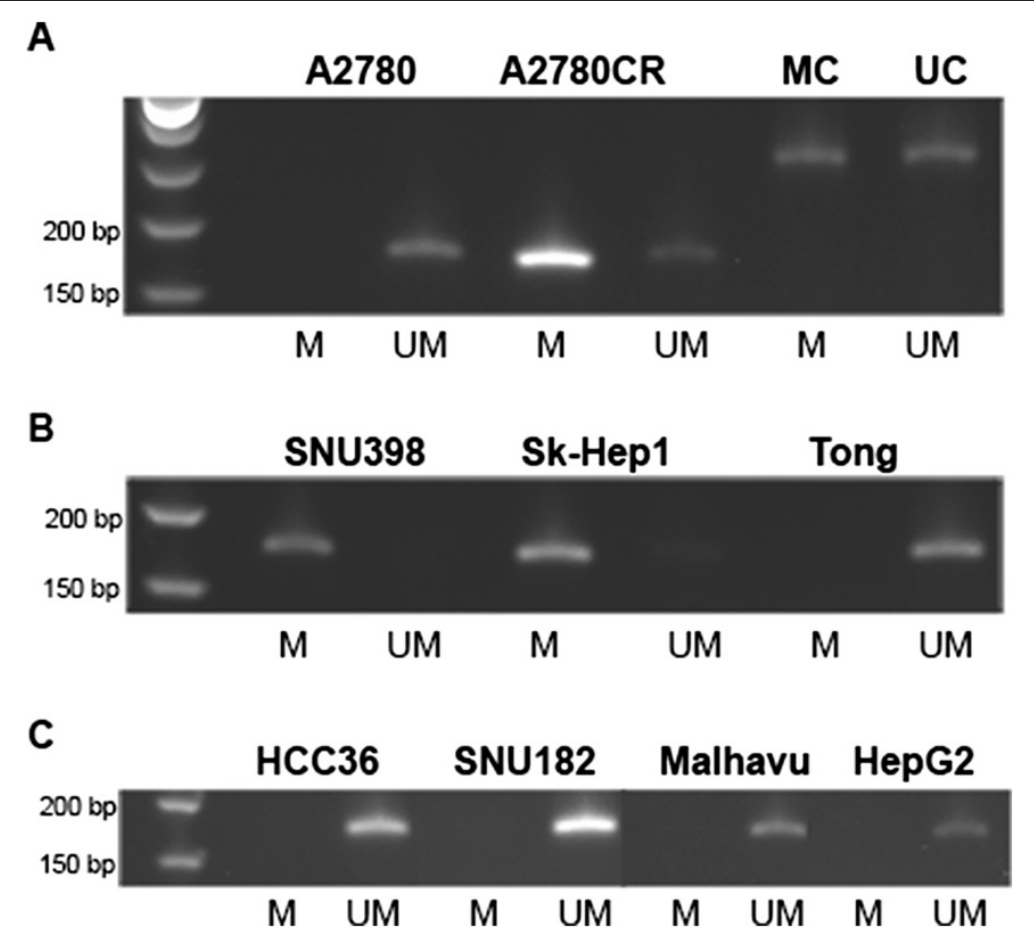

Figure 2 Methylation status of the ASS1 promoter in HCC cancer cell lines. DNA bisulfite conversion was performed directly from the cells and MSP was subsequently carried out to determine the methylation status of the ASS1 promoter. UM denotes unmethylated and M denotes methylated. Unmethylated and methylated controls (UC and MC) were included to assess bisulfite conversion efficiency. Expected band sizes are as follows: ASS1: 188 bp; control DNA: 274 bp. Data is representative of 3-4 independent experiments. (A) Control: ovarian cell lines A2780 and A2780CR. (B) ASS1-negative/low cells: SNU398, Sk-Hep1 and Tong. (C) ASS1-positive cells: HCC36, SNU182, Malhavu and HepG2. 


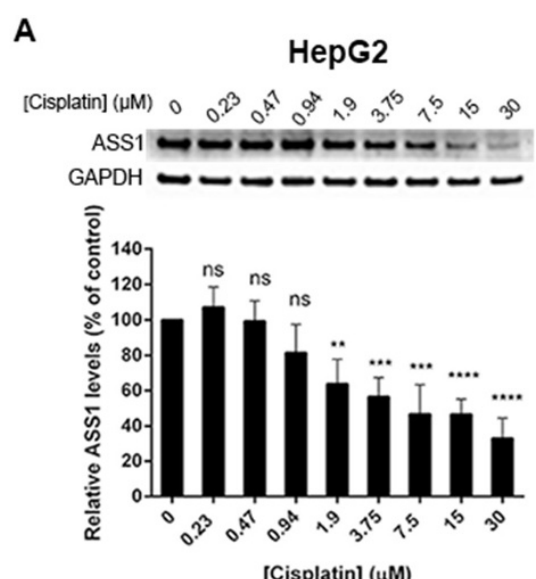

[Cisplatin] $(\mu \mathrm{M})$

C
B

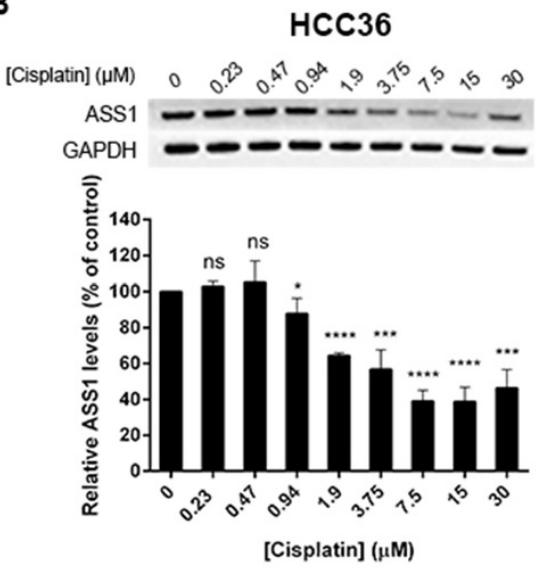

SNU182

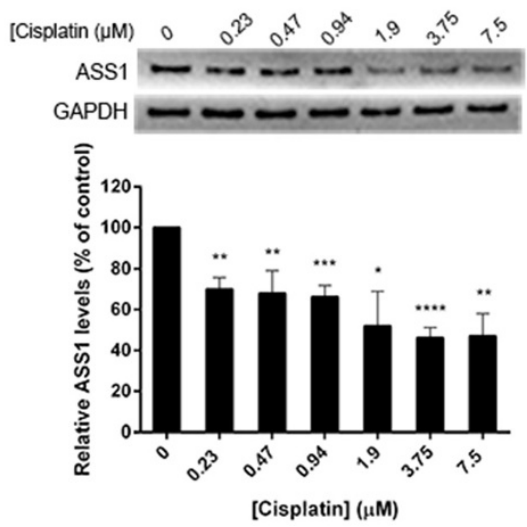

Figure 3 Cisplatin treatment down-regulates ASS1 protein in HCC cell lines. Cells were treated with indicated cisplatin concentrations in identical rows of a 96-well microplate. After $72 \mathrm{~h}$, triplicate samples were assessed for cell viability by reading the luminescence and lysates were made out of the remaining identical rows. Luminescence values were used to load equal amounts of protein and ASS1 expression was assessed by western blot. ASS1 levels were normalized to GAPDH at each cisplatin concentration and expressed relative to zero drug (100\%). The data are representative of three to four independent experiments. Error bars represent S.D. An unpaired t-test was conducted to determine the significance of the change in ASS1 protein levels after each cisplatin concentration treatment as compared to the untreated, or zero drug sample $\left({ }^{*} p<0.05,{ }^{* *} p<0.005,{ }^{* * *} p<0.001,{ }^{* * *} p<0.0001\right)$. (A) HepG2 cells. (B) HCC36 cells. (C) SNU182 cells.

higher concentrations of drug, and we found it challenging to use luminescence values to compare the total ASS1 and GAPDH protein at both $15 \mu \mathrm{M}$ and $30 \mu \mathrm{M}$ cisplatin with that in the lower concentration wells. For this reason, we have only quantified ASS1 to a concentration of $7.5 \mu \mathrm{M}$ in the SNU182 cell line (Figure 3C). As with the HepG2 and HCC36 cell lines, we do see a reduction of ASS1 expression in the SNU182 cell line with increasing cisplatin; however, the drop in ASS1 levels is not as gradual. The ASS1 expression decreases by approximately $50 \%$ relative to zero drug around the $\mathrm{IC}_{50}$ concentration of cisplatin. Taken together, our data indicate that cisplatin treatment reduces ASS1 protein expression in three HCC cell lines. Interestingly, we detect primarily unmethylated DNA at the ASS1 promoter for all three cell lines after the $72 \mathrm{~h}$ cisplatin treatment (data not shown), suggesting the mechanism of cisplatin down-regulation during these acute drug treatments is not epigenetic-based.

\section{ASS1 expression level during ADI-PEG 20 and cisplatin combination treatment is predominantly dictated by ADI-PEG 20}

The data thus far demonstrate a correlation between low ASS1 expression, resistance to cisplatin and sensitivity to ADI-PEG 20. Such a relationship provides a situation where one drug drives efficacy in an ASS1-negative cell line (ADI-PEG 20) and the other drives efficacy in an ASS1-high cell line (cisplatin), suggesting a favorable combination drug treatment. Our results demonstrate that cisplatin down-regulates ASS1 in three representative HCC cell lines. Thus, we wanted to determine the effect of the addition of ADI-PEG 20 to cisplatin on the ASS1 levels in these same cell lines. To determine 
the ASS1 expression during combination drug treatment, cells were simultaneously treated with cisplatin and ADI-PEG 20 in the same wells of a microplate, and then analyzed for ASS1 protein expression. Two concentrations of cisplatin that are known to reduce the ASS1 protein expression were chosen $(5 \mu \mathrm{M}$ and $7.5 \mu \mathrm{M})$ and increasing concentrations of ADI-PEG 20 were simultaneously added to the same wells. As expected, for HepG2 cells, treatment at both cisplatin concentrations alone causes a decline in ASS1 protein levels by approximately $50 \%$, which agrees with our previous results (Figure 3A). Figure 4A shows that as ADI-PEG 20 is added to cisplatin at both concentrations, the ASS1 levels increase. At both concentrations of cisplatin and

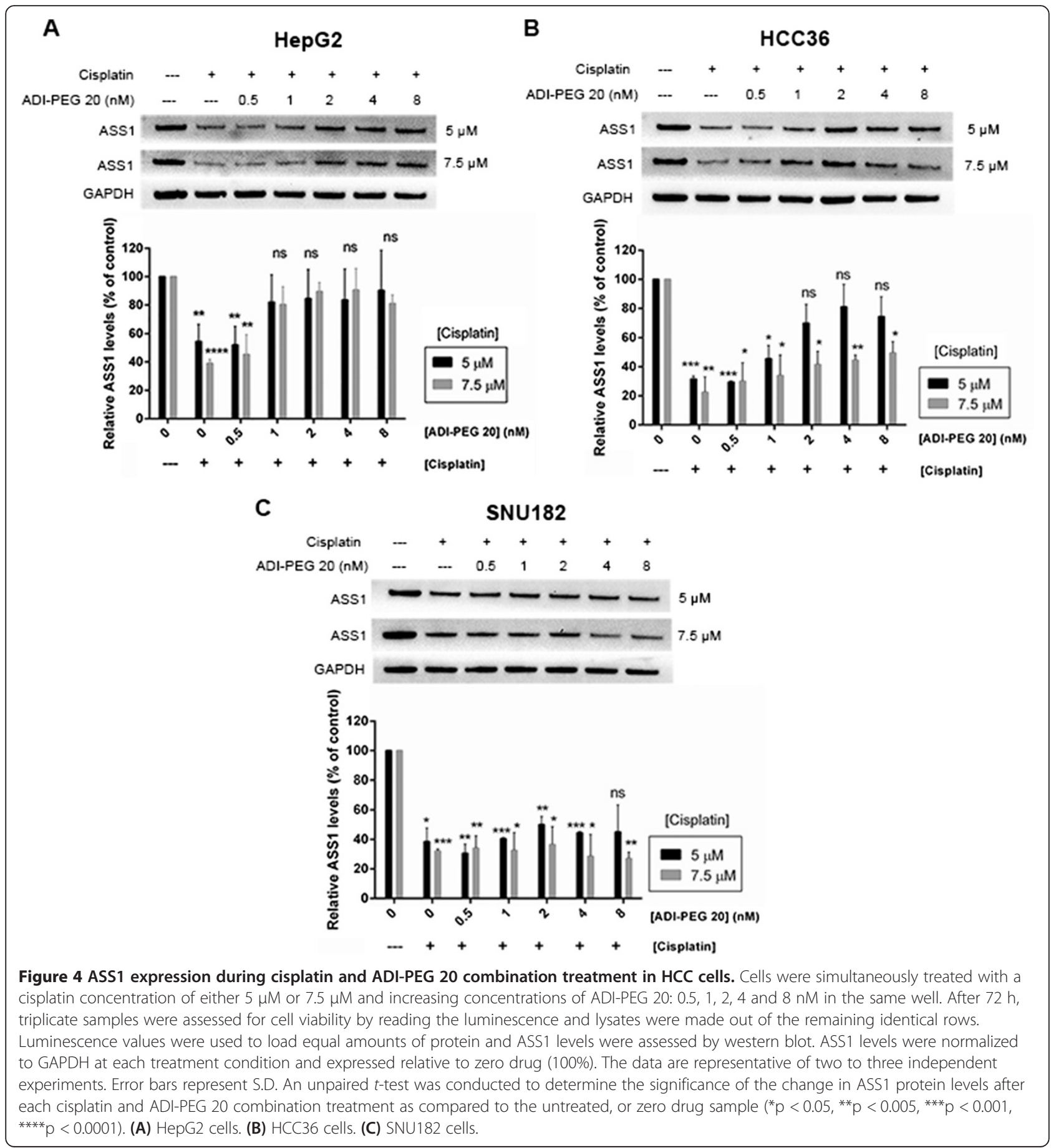


$8 \mathrm{nM}$ ADI-PEG $20(0.4 \mu \mathrm{g} / \mathrm{mL})$, the ASS1 expression is almost completely restored to that observed without drug treatment. For the HepG2 cell line, our results indicate that, in combination, ASS1 levels will be dictated by the ADI-PEG 20 at a cisplatin concentration around its $\mathrm{IC}_{50}$ value. The same experiment was performed with the HCC36 cell line and we observe a similar trend (Figure 4B). In agreement with previous results, treatment at both $5 \mu \mathrm{M}$ and $7.5 \mu \mathrm{M}$ cisplatin alone results in significant down-regulation of ASS1. At both concentrations of cisplatin, ASS1 levels do increase upon addition of ADI-PEG 20, but not to the same extent observed in the HepG2 cell line. We also performed this experiment at $2 \mu \mathrm{M}$ cisplatin, which is closer to the $\mathrm{IC}_{50}$ value for cisplatin in HCC36 cells, and detect a complete return of ASS1 at both 4 and 8 nM ADI-PEG 20 (data not shown). Thus, for the HCC36 cell line, the ASS1 levels will also be determined by the ADI-PEG 20 at a cisplatin concentration around its $\mathrm{IC}_{50}$ value.

The last cell line we investigated was SNU182, and surprisingly, we observe a different outcome. At both cisplatin concentrations, the ASS1 levels do not return, even at the highest concentration of ADI-PEG 20 (Figure 4C). The data suggest that in this cell line, ADI-PEG 20 addition is not sufficient to overcome the ASS1 downregulation induced by cisplatin. One possible explanation is that the SNU182 cell line does have a slightly lower $\mathrm{IC}_{50}$ value for cisplatin than the other 2 cell lines (Table 1 ). Thus, we examined the ASS1 levels in the SNU182 cell line at $2 \mu \mathrm{M}$ cisplatin, which is closer to its $\mathrm{IC}_{50}$ value of $1.3 \mu \mathrm{M}$. At $2 \mu \mathrm{M}$ cisplatin alone, we see $50 \%$ downregulation of ASS1. Interestingly, as ADI-PEG 20 is added, we do not observe any increase in ASS1 expression (data not shown), indicating that cisplatin will dictate ASS1 levels.

\section{Discussion}

The future for the treatment of arginine auxotrophic cancers lies in combination therapies. Several ADI-PEG 20 and cisplatin combination trials are planned. Therefore, understanding the correlation between ASS1 expression and cisplatin and ADI-PEG 20 sensitivities, as well as how ASS1 is regulated by both drugs could provide valuable information for trial design. For the first time, we have shown that there is a reciprocal relationship between ASS1 expression and cisplatin resistance in several human HCC cell lines. We have observed that resistance is specific to cisplatin, as sensitivity to other platinums and chemotherapeutic agents are unaffected by ASS1 expression. In addition, methylation of the ASS1 promoter does associate with sensitivity to ADI-PEG 20, and in HCC, also corresponds with cisplatin resistance, as previously demonstrated in ovarian cancer [22]. These findings suggest that the methylation status of the ASS1 promoter in tumors may predict sensitivity to arginine deprivation with ADI-PEG 20 and also support the future prospect of using methylation profiling to identify which HCC patients may benefit from either cisplatin or ADI-PEG 20.

Our novel data also indicate that cisplatin downregulates ASS1 protein expression in three HCC cell lines. How exactly cisplatin is affecting ASS1 levels during these acute treatments is currently unknown. Previously published studies indicate that ASS1 regulation occurs at the transcriptional level [37-40]. For example, it has been demonstrated that glutamine stimulated ASS1 expression in Caco- 2 cells through O-glycosylation of the transcription factor Sp1 [40], while expression of the ASS1 gene has been shown to be stimulated by interleukin-1 $\beta$ in Caco-2 cells through activation of the transcription factor nuclear factor- $\mathrm{\beta} \beta$ [38]. In melanoma cells, hypoxiainducible factor (HIF-1 $\alpha$ )-mediated transcriptional repression of ASS1 has been observed [31,33]. Other factors have been shown to positively or negatively regulate ASS1 expression. For example, cAMP increases ASS1 expression, while fatty acids cause suppression of this protein [41,42], and factors such as hormones and pro-inflammatory stimuli are also known to regulate ASS1 expression $[39,43]$.

Interestingly, there is suggestion that acquired resistance to cytotoxic agents occurs predominantly via epigenetic events $[44,45]$. A significant function for ASS1 in regulating platinum sensitivity via methylation of the ASS1 promoter has been observed in ovarian cancer utilizing the A2780 and A2780CR cell lines [22]. The A2780CR cell line was established by intermittent exposure of the parental A2780 cell line to stepwise, increasing concentrations of cisplatin up to a concentration of $8 \mu \mathrm{M}$ over a period of approximately 9 months [46]. This cell line was found to be 7.3-fold more resistant than the parental line, and it was indicated that this degree of resistance in the A2780CR cell line was stable for at least nine months during subculture in drug-free medium. Our experience with a commercially available A2780CR cell line is similar. We have observed that A2780CR does not express ASS1, is 12-fold more resistant to cisplatin than the parental cell line, and is completely methylated at the ASS1 promoter after being subcultured in cisplatin-free medium for 2 months. Given the similarities to ovarian cancer that we have observed in our HCC cell lines regarding ASS1 expression, methylation status of the ASS1 promoter and cisplatin resistance, we are currently establishing a HepG2 cisplatin-resistant (HepG2CR) cell line by progressively exposing HepG2 cells to increasing cisplatin. Preliminary data indicate a three-fold $\mathrm{IC}_{50}$ value increase for cisplatin in HepG2CR over the parental cell line after only one month of drug exposure. Once we acquire a more permanent resistant phenotype, we will determine the methylation status of HepG2CR and perform other 
analyses to understand the mechanisms of acquired cisplatin resistance in $\mathrm{HCC}$.

Several ADI-PEG 20 combination trials are ongoing or planned, including a combination with cisplatin for metastatic melanoma, ovarian cancer and other solid tumors, docetaxel for prostate and non-small cell lung cancer (NSCLC), doxorubicin for breast cancer, and cisplatin and pemetrexed for NSCLC and malignant pleural mesothelioma [20]. We have determined that ASS1 loss is a biomarker of cisplatin resistance and ADI-PEG 20 sensitivity, whereas ASS1 positivity is an indicator of cisplatin sensitivity and ADI-PEG 20 resistance in HCC cell lines. This observation suggests that a cisplatin and ADI-PEG 20 regimen should be superior to either drug alone for the treatment of HCC patients. To examine the potential for the use of ASS1 as a predictor in combination therapy, we sought to determine the ASS1 levels in HCC cells with both drugs present. Predictably, we found that the ASS1 protein levels will be dictated by one of the two drugs and is concentration-and cell-line dependent. In two of the three cell lines tested, the ASS1 levels seemed to be controlled by ADI-PEG 20, while cisplatin was able to maintain low ASS1 levels in the remaining cell line. Obviously, it is hard to predict clinical behavior from cell-based assays. We believe that ADI-PEG 20 will influence the ASS1 level of this twodrug regimen at more clinically relevant concentrations, resulting in higher ASS1 levels. This observation suggests that long term treatment with this combination could result in cisplatin resistant cells becoming cisplatin sensitive. Furthermore, several groups have observed that reduced expression of ASS1 is significantly associated with advanced tumor stage and an association with a worse clinical outcome [21-25]. These observations imply that the higher ASS1 levels present with the addition of ADI-PEG 20 to cisplatin may elicit better clinical outcomes for HCC patients. Extending these observations further to the clinic, our results suggest that while ASS1 may be a predictive biomarker for either ADI-PEG 20 or cisplatin as a single agent or pre-therapy, the status of this indicator may change by addition of the second drug and possibly evolve during tumor progression or metastasis. This concept of intratumoral heterogeneity within the same patient is growing in recognition and discordance of predictive or prognostic biomarker testing results between primary tumor and metastases or resistance acquisition has been reported in several tumor types [47].

\section{Conclusion}

Our data support the rationale of combining cisplatin and ADI-PEG 20 in the clinical treatment of HCC. We believe these two drugs will be complementary in a clinically relevant heterogeneous tumor. Furthermore, in
HCC, sensitivity to ADI-PEG 20 may be superior in cases that have relapsed after cisplatin-based chemotherapy. Extending beyond HCC to other cancers, our results suggest that in the combination setting, a patient does not necessarily need to have an ASS1-deficient tumor to reap benefit from an ADI-PEG 20 and cisplatin drug treatment.

\section{Abbreviations}

ASS1: Argininosuccinate synthetase; HCC: Hepatocellular carcinoma; ADI-PEG 20: PEGylated arginine deiminase; $I_{50}$ : Half maximal inhibitory concentration; GAPDH: Glyceraldehyde 3-phosphate dehydrogenase; MSP: Methylation-specific PCR; TSS: Transcription start site; HIF-1a: Hypoxia-inducible factor;

HepG2CR: HepG2 cisplatin-resistant cell line; NSCLC: Non-small cell lung cancer.

\section{Competing interests}

The authors declare that they have no competing interests.

\section{Authors' contributions}

JAM conceived and designed the study, performed experimental supervision and coordination, conducted data analysis and interpretation and wrote the manuscript. HTL and KCW acquired data and performed analysis. SKK assisted in methodology development, helped performed data analysis and interpretation and provided experimental supervision and technical assistance with tissue culture. JAT critically reviewed the scientific content of the manuscript and assisted with drafts. All authors read and approved the final manuscript.

\section{Acknowledgements}

The authors would like to thank Richard Showalter for supportive discussion and guidance with methylation-specific PCR (MSP) experiments, and Wei-Jong Shia for technical assistance with MSP experiments.

Received: 10 May 2014 Accepted: 22 August 2014

Published: 28 August 2014

\section{References}

1. Haines RJ, Pendelton LC, Eichler DC: Argininosuccinate syntase: at the center of arginine metabolism. Int J Biochem Mol Biol 2011, 2:8-23.

2. Dillon BJ, Prieto VG, Curley SA, Ensor CM, Holtsberg FW, Bomalaski JS, Clark MA: Incidence and distribution of argininosuccinate synthetase deficiency in human cancers: a method for identifying cancers sensitive to arginine deprivation. Cancer 2004, 100(4):826-833.

3. Ensor CM, Holtsberg FW, Bomalaski JS, Clark MA: Pegylated arginine deiminase (ADI-SS PEG20,000 mw) inhibits human melanomas and hepatocellular carcinomas in vitro and in vivo. Cancer Res 2002, 62(19):5443-5450.

4. Szlosarek PW, Klabatsa A, Pallaska A, Sheaff M, Smith P, Crook T, Grimshaw MJ, Steele JP, Rudd RM, Balkwill FR, Fennell DA: In vivo loss of expression of argininosuccinate synthetase in malignant pleural mesothelioma is a biomarker for susceptibility to arginine depletion. Clin Cancer Res 2006, 12(23):7126-7131.

5. Bowles TL, Kim R, Galante J, Parsons CM, Virudachalam S, Kung HJ, Bold RJ: Pancreatic cancer cell lines deficient in argininosuccinate synthetase are sensitive to arginine deprivation by arginine deiminase. Int I Cancer 2008, 123(8):1950-1955.

6. Kim RH, Coates JM, Bowles TL, McNerney GP, Sutcliffe J, Jung JU, GandourEdwards R, Chuang FY, Bold RJ, Kung HJ: Arginine deiminase as a novel therapy for prostate cancer induces autophagy and caspaseindependent apoptosis. Cancer Res 2009, 69(2):700-708.

7. Yoon CY, Shim YJ, Kim EH, Lee JH, Won NH, Kim JH, Park IS, Yoon DK, Min BH: Renal cell carcinoma does not express argininosuccinate synthetase and is highly sensitive to arginine deprivation via arginine deiminase. Int J Cancer 2007, 120(4):897-905.

8. Kelly MP, Jungbluth AA, Wu BW, Bomalaski J, Old L, Ritter G: Arginine deiminase PEG20 inhibits growth of small cell lung cancers lacking expression of argininosuccinate synthetase. Br J Cancer 2012, 106(2):324-332. 
9. Frith $A E$, Hirbe $A C$, Van Tine BA: Novel pathways and molecular targets for the treatment of sarcoma. Curr Oncol Rep 2013, 15(4):378-385.

10. Delage B, Fennell DA, Nicholson L, McNeish I, Lemoine NR, Crook T, Szlosarek PW: Arginine deprivation and argininosuccinate synthetase expression in the treatment of cancer. Int J Cancer 2010, 126(12):2762-2772.

11. Szlosarek PW, Grimshaw MJ, Wilbanks GD, Hagemann T, Wilson JL, Burke F, Stamp G, Balkwill FR: Aberrant regulation of argininosuccinate synthetase by TNF-alpha in human epithelial ovarian cancer. Int J Cancer 2007, 121(1):6-11

12. Feun L, Savaraj N: Pegylated arginine deiminase: a novel anticancer enzyme agent. Expert Opin Investig Drugs 2006, 15(7):815-822.

13. Ott PA, Carvajal RD, Pandit-Taskar N, Jungbluth AA, Hoffman EW, Wu BW, Bomalaski JS, Venhaus R, Pan L, Old L, Pavlick AC, Wolchok J: Phase I/II study of pegylated arginine deiminase (ADI-PEG 20) in patients with advanced melanoma. Invest New Drugs 2013, 31(2):425-434.

14. Yang TS, Lu SN, Chao Y, Sheen IS, Lin CC, Wang TE, Chen SC, Wang JH, Liao LY, Thomson JA, Wang-Peng J, Chen PJ, Chen LT: A randomised phase II study of pegylated arginine deiminase (ADI-PEG 20) in Asian advanced hepatocellular carcinoma patients. $\mathrm{Br} J$ Cancer 2010 103(7):954-960.

15. Izzo F, Marra P, Beneduce G, Castello G, Vallone P, De Rosa V, Cremona F, Ensor CM, Holtsberg FW, Bomalaski JS, Clark MA, Ng C, Curley SA: Pegylated arginine deiminase treatment of patients with unresectable hepatocellular carcinoma: results from phase I/II studies. J Clin Oncol 2004, 22(10):1815-1822.

16. Ascierto PA, Scala S, Castello G, Daponte A, Simeone E, Ottaiano A, Beneduce G, De Rosa V, Izzo F, Melucci MT, Ensor CM, Prestayko AW Holtsberg FW, Bomalaski JS, Clark MA, Savaraj N, Feun LG, Logan TF: Pegylated arginine deiminase treatment of patients with metastatic melanoma: results from phase I and II studies. J Clin Oncol 2005, 23(30):7660-7668.

17. Glazer ES, Piccirillo M, Albino V, Di Giacomo R, Palaia R, Mastro AA, Beneduce G, Castello G, De Rosa V, Petrillo A, Ascierto PA, Curley SA, Izzo F: Phase II study of pegylated arginine deiminase for nonresectable and metastatic hepatocellular carcinoma. J Clin Oncol 2010, 28(13):2220-2226.

18. Feun LG, Marini A, Walker G, Elgart G, Moffat F, Rodgers SE, Wu CJ, You M, Wangpaichitr M, Kuo MT, Sisson W, Jungbluth AA, Bomalaski J, Savaraj N: Negative argininosuccinate synthetase expression in melanoma tumours may predict clinical benefit from arginine-depleting therapy with pegylated arginine deiminase. Br J Cancer 2012, 106(9):1481-1485.

19. Szlosarek PW, Steele JP, Sheaff MT, Avril NE, Szysko T, Ellis S, et al: A randomised phase II trial of pegylated arginine deiminase (ADI-PEG20) in patients with malignant pleural mesothelioma (MPM). In World Conference on Lung Cancer. Sydney; 2013. Abstr no. MO09.02.

20. Phillips MM, Sheaff MT, Szlosarek PW: Targeting arginine-dependent cancers with arginine-degrading enzymes: opportunities and challenges. Cancer Res Treat 2013, 45(4):251.

21. Kobayashi E, Masuda M, Nakayama R, Ichikawa H, Satow R, Shitashige M, Honda K, Yamaguchi U, Shoji A, Tochigi N, Morioka H, Toyama Y, Hirohashi S, Kawai A, Yamada T: Reduced argininosuccinate synthetase is a predictive biomarker for the development of pulmonary metastasis in patients with osteosarcoma. Mol Cancer Ther 2010, 9(3):535-544.

22. Nicholson LJ, Smith PR, Hiller L, Szlosarek PW, Kimberley C, Sehouli J, Koensgen D, Mustea A, Schmid P, Crook T: Epigenetic silencing of argininosuccinate synthetase confers resistance to platinum-induced cell death but collateral sensitivity to arginine auxotrophy in ovarian cancer. Int J Cancer 2009, 125(6):1454-1463.

23. Huang HY, Wu WR, Wang YH, Wang JW, Fang FM, Tsai JW, Li SH, Hung HC, Yu SC, Lan J, Shiue YL, Hsing CH, Chen LT, Li CF: ASS1 as a novel tumor suppressor gene in myxofibrosarcomas: aberrant loss via epigenetic DNA methylation confers aggressive phenotypes, negative prognostic impact, and therapeutic relevance. Clin Cancer Res 2013, 19(11):2861-2872.

24. Allen MD, Luong P, Hudson C, Leyton J, Delage B, Ghazaly E, Cutts R, Yuan M, Syed N, Lo Nigro C, Lattanzio L, Chmielewska-Kassassir M, Tomlinson I, Roylance R, Whitaker HC, Warren AY, Neal D, Frezza C, Beltran L, Jones $L_{\text {, }}$ Chelala C, Wu BW, Bomalaski JS, Jackson RC, Lu YJ, Crook T, Lemoine NR, Mather S, Foster J, Sosabowski J, et al: Prognostic and therapeutic impact of argininosuccinate synthetase 1 control in bladder cancer as monitored longitudinally by PET imaging. Cancer Res 2014, 74(3):896-907.

25. Qiu F, Chen YR, Liu X, Chu CY, Shen LJ, Xu J, Gaur S, Forman HJ, Zhang H, Zheng S, Yen Y, Huang J, Kung HJ, Ann DK: Arginine starvation impairs mitochondrial respiratory function in ASS1-deficient breast cancer cells. Sci Signal 2014, 7(319):ra31.

26. Syed N, Langer J, Janczar K, Singh P, Lo Nigro C, Lattanzio L, Coley HM, Hatzimichael E, Bomalaski J, Szlosarek P, Awad M, O'Neil K, Roncaroli F, Crook T: Epigenetic status of argininosuccinate synthetase and argininosuccinate lyase modulates autophagy and cell death in glioblastoma. Cell Death Dis 2013, 4:e458.

27. Delage B, Luong P, Maharaj L, O'Riain C, Syed N, Crook T, Hatzimichael E Papoudou-Bai A, Mitchell TJ, Whittaker SJ, Cerio R, Gribben J, Lemoine N, Bomalaski J, Li CF, Joel S, Fitzgibbon J, Chen LT, Szlosarek PW: Promoter methylation of argininosuccinate synthetase-1 sensitises lymphomas to arginine deiminase treatment, autophagy and caspase-dependent apoptosis. Cell Death Dis 2012, 3:e342.

28. Wei SH, Chen CM, Strathdee G, Strathdee G, Harnsomburana J, Shyu CR, Rahmatpanah F, Shi H, Ng SW, Yan PS, Nephew KP, Brown R, Huang TH: Methylation microarray analysis of late-stage ovarian carcinomas distinguishes progression-free survival in patients and identifies candidate epigenetic markers. Clin Cancer Res 2002, 8(7):2246-2252.

29. El-Serag HB, Rudolph KL: Hepatocellular carcinoma: epidemiology and molecular carcinogenesis. Gastroenterology 2007, 132(7):2557-2576.

30. Schafer DF, Sorrell MF: Hepatocellular carcinoma. Lancet 1999, 353:1253-1257.

31. Tsai WB, Aiba I, Lee SY, Feun L, Savaraj N, Kuo MT: Resistance to arginine deiminase treatment in melanoma cells is associated with induced argininosuccinate synthetase expression involving c-Myc/HIF-1alpha/ Sp4. Mol Cancer Ther 2009, 8(12):3223-3233.

32. Savaraj N, Wu C, Kuo MT, You M, Wangpaichitr M, Robles C, Spector S, Feun $\mathrm{L}$ : The relationship of arginine deprivation, argininosuccinate synthetase and cell death in melanoma. Drug Target Insights 2007, 2:119-128.

33. Feun L, You M, Wu CJ, Kuo MT, Wangpaichitr M, Spector S, Savaraj N: Arginine deprivation as a targeted therapy for cancer. Curr Pharm Des 2008, 14(11):1049-1057.

34. Savaraj N, You M, Wu C, Wangpaichitr M, Kuo MT, Feun LG: Arginine deprivation, autophagy, apoptosis (AAA) for the treatment of melanoma. Curr Mol Med 2010, 10(4):405-412

35. Chow AK, Ng L, Sing Li H, Cheng CW, Lam CS, Yau TC, Cheng PN, Fan ST, Poon RT, Pang RW: Anti-tumor efficacy of a recombinant human arginase in human hepatocellular carcinoma. Curr Cancer Drug Targets 2012, 12(9):1233-1243.

36. Helleman J, Jansen MP, Span PN, van Staveren IL, Massuger LF, Meijer-van Gelder ME, Sweep FC, Ewing PC, van der Burg ME, Stoter G, Nooter K, Berns EM: Molecular profiling of platinum resistant ovarian cancer. Int J Cancer 2006, 118(8):1963-1971.

37. Goodwin BL, Pendleton LC, Levy MM, Solomonson LP, Eichlere DC: Tumor necrosis factor-alpha reduces argininosuccinate synthase expression and nitric oxide production in aortic endothelial cells. Am J Physiol Heart Circ Physiol 2007, 293:H1115-H1121.

38. Brasse-Lagnel C, Lavoinne A, Loeber D, Fairand A, Bole-Feysot C, Deniel N, Husson A: Glutamine and interleukin-1beta interact at the level of Sp1 and nuclear factor-kappaB to regulate argininosuccinate synthetase gene expression. FEBS J 2007, 274(20):5250-5262.

39. Husson A, Brasse-Lagnel C, Fairand A, Renouf S, Lavoinne A: Argininosuccinate synthetase from the urea cycle to the citrulline-NO cycle. Eur J Biochem 2003, 270(9):1887-1899.

40. Brasse-Lagnel C, Fairand A, Lavoinne A, Husson A: Glutamine stimulates argininosuccinate synthetase gene expression through cytosolic O-glycosylation of Sp1 in Caco-2 cells. J Biol Chem 2003, 278(52):52504-52510.

41. Morris SM, Moncman CL, Rand KD, Dizikes GJ, Cederbaum SD, O'Brien WE: Regulation of mRNA levels for five urea cycle enzymes in Rat liver by diet, cyclim AMP, and glucocorticoids. Arch Biochem Biophys 1987, 256:343-353.

42. Tomomura M, Tomomura A, Abdullah DM, Musa AA, Saheki T: Long-chain fatty acids suppress the induction of urea cycle enzyme genes by glucocorticoid action. FEBS Lett 1996, 399:310-312.

43. Zhang WY, Gotoh T, Oyadomari S, Mori M: Coinduction of inducible nitric oxide synthase and arginine recycling enzymes in cytokine-stimulated PC12 cells and high output production of nitric oxide. Mol Brain Res 2000, $83: 1-8$.

44. Glasspool RM, Teodoridis JM, Brown R: Epigenetics as a mechanism driving polygenic clinical drug resistance. Br J Cancer 2006, 94(8):1087-1092. 
45. Teodoridis JM, Strathdee G, Brown R: Epigenetic silencing mediated by CpG island methylation: potential as a therapeutic target and as a biomarker. Drug Resist Updat 2004, 7(4-5):267-278.

46. Behrens BC, Hamilton TC, Masuda H, Grotzinger KR, Whang-Peng J, Louie KG, Knutsen T, McKoy WM, Young RC, Ozols RF: Characterization of a cis-diamminedichloroplatinum(II)-resistant human ovarian cancer cell line and its Use in evaluation of platinum analogues. Cancer Res 1987, 47:414-418.

47. Bedard PL, Hansen AR, Ratain MJ, Siu LL: Tumour heterogeneity in the clinic. Nature 2013, 501(7467):355-364.

doi:10.1186/1471-2407-14-62

Cite this article as: McAlpine et al.: Down-regulation of

argininosuccinate synthetase is associated with cisplatin resistance in hepatocellular carcinoma cell lines: implications for PEGylated arginine deiminase combination therapy. BMC Cancer 2014 14:621.

\section{Submit your next manuscript to BioMed Central and take full advantage of:}

- Convenient online submission

- Thorough peer review

- No space constraints or color figure charges

- Immediate publication on acceptance

- Inclusion in PubMed, CAS, Scopus and Google Scholar

- Research which is freely available for redistribution 